\title{
Effect of fungal colonization on mechanical performance of cork
}

\author{
Cristina Silva Pereira ${ }^{\mathrm{a}, *}$, Giselle A. M. Soares ${ }^{\mathrm{a}}$, Ana C. Oliveira ${ }^{\mathrm{a}}$, Maria Emília Rosa ${ }^{\mathrm{b}}$, \\ Helena Pereira $^{\mathrm{c}}$, Nuno Moreno ${ }^{\mathrm{d}}$, Maria Vitória San Romão ${ }^{\mathrm{a}, \mathrm{e}}$ \\ ${ }^{a} I B E T / I T Q B-U N L$, Instituto de Biologia Experimental e Tecnológica/ Instituto de Tecnologia Química e Biológica, \\ Universidade Nova de Lisboa, Oeiras, Portugal \\ ${ }^{\mathrm{b}}$ IST, Instituto Superior Técnico, Universidade Técnica de Lisboa, Lisboa Portugal \\ ${ }^{\mathrm{c}}$ CEF-ISA, Centro de Estudos Florestais-Instituto Superior de Agronomia, Universidad Técnica de Lisboa, Lisboa, Portugal \\ ${ }^{\mathrm{d}}$ IGC, Instituto Gulbenkian de Ciência, Oeiras, Portugal \\ ${ }^{\mathrm{e}}$ EVN, Estação Vitivinicola Nacional, Dois Portos, Portugal
}

Received 14 December 2005; received in revised form 3 March 2006; accepted 4 March 2006

Available online 27 April 2006

\begin{abstract}
The industrialization of traditional processes relies on the scientific ability to understand the empirical evidence associated with traditional knowledge. Cork manufacturing includes one operation known as stabilization, where humid cork slabs are extensively colonized by fungi. The implications of fungal growth on the chemical quality of cork through the analysis of putative fungal metabolites have already been investigated. However, the effect of fungal growth on the mechanical properties of cork remains unexplored. This study investigated the effect of cork colonization on the integrity of the cork cell walls and their mechanical performance. Fungal colonization of cork by Chrysonilia sitophila, Mucor plumbeus Penicillium glabrum, P. olsonii, and Trichoderma longibrachiatum was investigated by microscopy. Growth occurred primarily on the surface of the cork pieces, but mycelium extended deeper into the cork layers, mostly via lenticular channels and by hyphal penetration of the cork cell wall.

In this first report on cork decay in which specific correlation between fungal colonization and mechanical proprieties of the cork has been investigated, all colonizing fungi except $C$. sitophila, reduced cork strength, markedly altering its viscoelastic behaviour and reducing its Young's modulus.
\end{abstract}

(C) 2006 Elsevier Ltd. All rights reserved.

Keywords: Biodegradation of cork; Fungi; Mechanical properties; Visco-elastic behaviour

\section{Introduction}

Cork is the bark of Quercus suber L., an extremely important forest tree in Portugal, Spain and some Mediterranean countries, and Portugal is the world leader in cork transformation. It is a lightweight material with good thermal insulating properties, and is also elastic, compressible and impermeable to gases or liquids (Lopes et al., 2001; Mano, 2002). It is the most suitable material for the manufacture of products which rely on its high compressibility, e.g. wine stoppers, soles of shoes and floor coverings (Fortes et al., 2004). Cork stoppers are the most

\footnotetext{
*Corresponding author. Tel.: + $351214469568 / 554$ fax: +351214411277 .

E-mail address: spereira@itqb.unl.pt (C. Silva Pereira).
}

valuable industrial product (Fortes et al., 2004). During the last decade, the cork stopper industry has become increasingly vulnerable as a result of the introduction of products such as synthetic stoppers. The exploitation of other uses for cork, e.g. floor coverings and hightechnology applications such as cork insulation in NASA rockets, relies on an understanding of the cork manufacturing process and identification of the key factors for good mechanical performance of the product, even after long periods of use in the most adverse environments.

Cork is a homogeneous tissue of thin-walled cells, regularly arranged without intercellular spaces as an irregular polyhedral packed in columns parallel to the radial direction of the tree (Pereira et al., 1987). The simplicity of the cellular arrangement and structure of the cork cells is similar to wood (Clause, 1997; Geoffrey, 1994). 
The cell-wall composition resembles that in wood with the addition of suberin (45\%) (Lopes et al., 2000, 2001; Pereira, 1988), which is responsible for the unique and remarkable properties of cork. The relative simplicity of cork tissue makes it easily examined by microscopy, simplifying the observation and identification of putative fungal structures in colonized tissue.

Although fungal biodegradation of biomaterials such as wood or cork is an important ecological process that recycles organic matter and contributes to environmental sustainability (Blanchette, 2000), these processes also impact negatively on the preservation of such materials, thus affecting industry and the economy. Extensive cork decay depends on the ability of fungi to degrade its most abundant constituent-suberin, which is located in the innermost layer of the cell wall (Pereira et al., 1987). Although cork is normally considered recalcitrant to microbial degradation (Kolattukudy, 1981), recently some fungi have been reported to degrade suberin efficiently (Centeno and Calvo, 2001; Riu et al., 1997).

The understanding of cork decay processes is important for the production of cork sub-products. It includes one operation, known as cork slab stabilization (Fortes et al., 2004), where the superficial area of the moist, boiled cork slabs is extensively colonized by fungi (Danesh et al., 1997; Oliveira et al., 2003). The boiling step is a standard procedure, necessary to obtain a more homogeneous cellular structure, through the expansion of the collapsed and wrinkled cork cells, and it results in a material with adequate moisture content and flexibility from which stoppers for bottles can be punched out (Rosa et al., 1990).

Nowadays, probably due to scale-up and modern industrialization, the traditional dominant colonizing fungus, Chrysonilia sitophila (Mont.) Arx, has been replaced by a more complex consortium. In this system, several fungal genera, especially Penicillium, coexist with $C$. sitophila (Danesh et al., 1997; Oliveira et al., 2003). The effect of fungal colonization on the chemical quality of cork has been investigated through the analysis of fungal metabolites, especially those that may impart unpleasant sensory alterations to bottled wines (Alvarez-Rodriguez et al., 2002; Coque et al., 2003; Silva Pereira et al., 2000a,b). Nevertheless, the impact of cork fungal colonization on the mechanical and physical quality of cork has yet to be characterized. Likewise, it is not known whether the fungal colonization during cork manufacturing may further endanger the preservation of the mechanical performance of cork.

To the authors' knowledge, this is the first report on the effect of decay by fungi on the mechanical properties of cork. Additionally, a correlation between mechanical properties and colonizing fungal species is attempted. This correlation would appear to be technologically important, reveals also the need to understand better the processes behind the decay of suberin - a complex polymer. It opens further research opportunities, mostly those concerning the microbiological processes behind degradability of high recalcitrant plant biocomposites.

\section{Materials and methods}

\subsection{Materials}

All cork samples used in this study were obtained from the cork producers Amorim and Irmãos (Sta Maria de Lamas, Portugal). The fungal strains used were from the Instituto de Biologia Experimental e Tecnológica (IBET) culture collection and had been previously isolated from cork samples purchased from several Portuguese cork industries. They were C. sitophila (DSM16514), Mucor plumbeus Bonord (DSM 16513), Penicillium glabrum (Wehmer) Westling (DSM 16516), P. olsonii Bainier and Sartory (DSM 16515) and Trichoderma longibrachiatum Rifai (DSM 16517) (Oliveira et al., 2003; Soares et al., 2003).

\subsection{Cork tissue preparation}

Cork samples were collected from boiled Portuguese industrial cork slabs and were immediately cut into approx. $8-$ or $1-\mathrm{cm}^{3}$ cork cubes, some of which were sterilised by $\gamma$-irradiation $(30 \mathrm{kGy})$. Thick $(200 \mu \mathrm{m})$ sections were cut from the irradiated cork cubes in tangential and transverse planes using a Leica Vibratome microtome. Prior to the start of each experiment, cork cubes of both sizes and thick sections were boiled in distilled water for $1 \mathrm{~h}$ and $15 \mathrm{~min}$, respectively, to provide cork tissues with adequate moisture for fungal growth.

\subsection{Scanning electron microscopy (SEM)}

Non-irradiated boiled cubes (approx. $8 \mathrm{~cm}^{3}$ ) were incubated for 3 months at $27{ }^{\circ} \mathrm{C}$ and $95 \% \mathrm{RH}$, under a photoperiod of $16 \mathrm{~h}$ day (Fitoclima s600). After incubation, the superficial mycelium on the cork cubes was removed by washing with an excess of sodium hypochlorite:ethanol:water (5:12:3). Each cube was further cut into eight identical cubes of $1 \mathrm{~cm}^{3}$ and their facets labelled in accordance to the parent cube. Like so, each facet of the $1 \mathrm{~cm}^{3}$ cube was categorized as either exterior (superficial) or interior, which refers to their position relative to the surface of the original cork cube. The tissues were dried using liquid nitrogen in a critical point freeze drying apparatus. The critically dried specimens were sputter coated with gold palladium, $200 \AA$ thick, and examined by SEM. Photos were labelled as interior cube sections only when taken near the interception point of the inner edges of the inner facets.

\subsection{Fungal growth on a cork-based medium}

Cork-based medium contains per liter of water $1 \mathrm{~g}$ of cork powder (previously sterilized by $\gamma$ radiation) and $1.5 \mathrm{~g}$ of agar (Merck, Germany). The sterilized cork powder is added to the remaining medium and distributed onto Petri dishes (ca. $15 \mathrm{~mL}$ ). To prepare the inoculum mycelium discs, of ca. $20 \mathrm{~mm}^{2}$, were cut with a sterile glass tube from the edge of a 8-day fungal culture grown onto Malt Extract Media (Merck). The cork-based solid medium was then centrally inoculated using the mycelium discs and incubated at $25^{\circ} \mathrm{C}$ and ca. $95 \%$ RH. Each experiment was done in triplicate and the colonial diameter measured, at specific intervals until stationary growth stage was achieved, using a precision measuring caliper.

\subsection{Fungal culture conditions}

After boiling, the irradiated cork samples (cubes and 200- $\mu \mathrm{m}$ sections) were immediately submerged in a spore suspension prepared as previously described (Silva Pereira et al., 2000b). The absorbance of the spore suspension was adjusted to 0.4 at $450 \mathrm{~nm}$ in each case, corresponding to ca. $10^{6}-10^{7}$ spores per $\mathrm{mL}$. To guarantee satisfactory inoculation of the 
cork, the samples were kept in the spore suspension under controlled orbital agitation at $140 \mathrm{rpm}$ at $27^{\circ} \mathrm{C}$ for $30-60 \mathrm{~min}$. In uninoculated controls, $0.8 \% \mathrm{NaCl}(\mathrm{w} / \mathrm{v})$ saline solution was used instead of spore suspensions. All cubes and thick sections were then incubated at $27^{\circ} \mathrm{C}$ and $95 \% \mathrm{RH}$, under a photoperiod of $16 \mathrm{hday}^{-1}$. After the required incubation period, the water activity of the cork tissues $\left(a_{\mathrm{w}}\right)$ was measured using a hygrometer (Model DP680, Protimeter Ltd., Marlow, UK). Prior to analysis, superficial fungal mycelium on the samples was removed by washing with an excess of sodium hypochlorite:ethanol:water (5:12:3) and by superficial mopping with a sterile tissue. Cork cubes for use in the compression tests were dried at $40{ }^{\circ} \mathrm{C}$ for $24 \mathrm{~h}$, to maintain the moisture level in all cork cubes, which otherwise could have caused discrepancy in compression measurements.

\subsection{Compression tests}

Samples for mechanical testing were cut from irradiated cork slabs as ca. $8-\mathrm{cm}^{3}$ cubes with ca. 20 -mm edges, as previously described, and the sides perpendicular to each of the three main axes of the cork (Rosa and Fortes, 1988). Triplicate inoculated and control samples were used for each fungus tested. To obtain the compression stress-strain curves the cork cubes were compressed along the radial axis in a testing machine (Shimadzu AG-5000) at a $2 \mathrm{~mm} \mathrm{~min}^{-1}$ crosshead speed (the nominal strain rate, obtained by dividing the crosshead speed by the initial length of the cube edge, was approx. $1.5 \times 10^{-3} \mathrm{sec}^{-1}$ ).

\subsection{Fluorescence microscopy}

Prior to fluorescence detection, 200- $\mu \mathrm{m}$ thick radial and tangential sections were cut from control and inoculated $1-\mathrm{cm}^{3}$ cubes. The cork sections were then fixed for $10 \mathrm{~min}$ in $2 \%(\mathrm{v} / \mathrm{v})$ formaldehyde in phosphate buffered saline (PBS), $\mathrm{pH} 7.4$, containing $\left(\mathrm{l}^{-1}\right) 8.0 \mathrm{~g} \mathrm{NaCl} ; 0.2 \mathrm{~g} \mathrm{KCl} ; 0.2 \mathrm{~g}$ $\mathrm{KH}_{2} \mathrm{PO}_{4}$ and $1.15 \mathrm{~g} \mathrm{Na}_{2} \mathrm{HPO}_{4}$ (Mendoza et al., 1995). The sections were then washed with PBS and labelled for more $30 \mathrm{~min}$ in a $10 \mu \mathrm{g} \mathrm{ml}^{-1}$ solution of chitin-labelling wheat germ agglutinin (WGA) conjugated with Alexa Fluor 660 (Molecular Probes Inc., Washington DC, USA) in PBS. The samples were examined using an optical Olympus BH2 microscope and images were recorded with an Olympus DP11 digital camera. The cork sections were also examined under a wide-field microscope (Leica DMRA2) with a $20 \times 0.5 \mathrm{NA}$ or an oil immersion $63 \times 1.4$ NA objective lens. The filter set was better suited for lower wavelengths, but a good signal was observed with a CoolSnap HQ camera (Roper Scientific). For fluorescence detection of the fungal hyphae, a Leica confocal (SP2/AOBS) system with a dry $20 \times 0.7 \mathrm{NA}$ objective lens was used, with a spectral gate between 670 and $750 \mathrm{~nm}$ for fluorophore detection. The excitation lines were repectively $488 \mathrm{~nm}$ for the auto-fluorescence of the cork and $633 \mathrm{~nm}$ for the fluorophore Alexa 660 .

\section{Results and discussion}

When cork samples taken from the stabilization stage of cork production (at this time superficially colonized by several fungi) were evaluated to determine whether there was a risk of further fungal degradation by incubating non-irradiated, boiled cork cubes for 3 months at high humidity levels, SEM clearly indicated the presence of fungal hyphae in both the superficial and inner layers of the cork (Fig. 1(a),(b)). The hyphae appeared to be preferentially located inside lenticular channels in the cork tissues (Fig. 1(c)), but some completely perforated the cell wall, reaching the hollow interior of the cells (Fig. 1(b)). The boiling operation has destroyed all the superficial mycelium and made improbable the survivability of viable inoculum in the most superficial layers of the cork cube. The newly
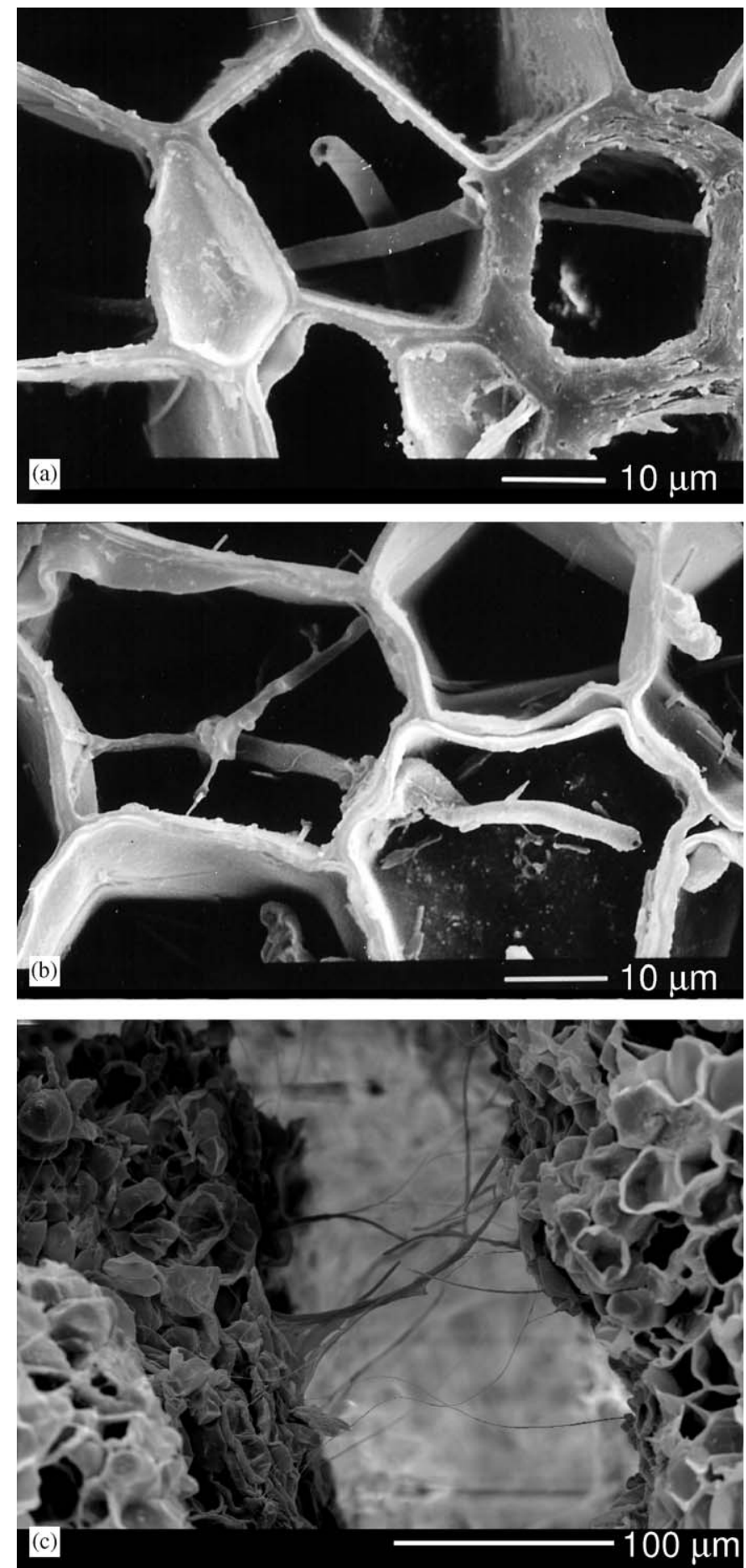

Fig. 1. SEM of non-irradiated $8-\mathrm{cm}^{3}$ cork cubes incubated for three months at $25^{\circ} \mathrm{C}$ and $95 \%$ R.H.: (a) exterior cork tangential section showing fungal colonization inside hollow cork cells; (b) interior tangential section showing hyphal perforation of cell wall; and (c) fungal mycelium accumulation in a lenticular channel of the cork tissues.

formed mycelium, detected after incubation, suggests that fungal inoculum (spores or hyphae) was conserved viable, maybe deep in the cellular layers of the cork tissues. This survived the boiling treatments and the long storage periods and under the appropriate growth conditions developed further mycelium. 


\subsection{Alteration of mechanical properties with fungal colonization}

The fungal species selected from the most frequent corkcolonizing consortium (Danesh et al., 1997; Oliveira et al., 2003), viz. C. sitophila, M. plumbeus, P. glabrum, P. olsonii and $T$. longibrachiatum, are widely distributed in soil and on plants, decaying fruits, vegetables and wood. Much is known about colonization and degradation of wood by fungi, but, as mentioned previously, the consequences of fungal colonization for the mechanical performance of cork has been studied little (Carlite and Watkinson, 1994). All fungi tested here (Table 1) actively grew on cork, their growth rates being indicative of cork functioning as a substrate for fungal growth. Nevertheless, there is still a lack of information on the ability of individual fungi to penetrate to inner cork layers, perforate the suberinized walls and alter the nanostructure of the wall.

In compression tests, the load is applied to the specimen placed on the bed plate of the testing machine through the movable crosshead, which moves downward (shortening the specimen length parallel to the compression axis) with a constant displacement speed. During the compression test, a load-crosshead displacement curve is recorded. To characterize the material, stress-strain $(\varepsilon-\sigma)$ curves (average of three distinct experiments) are required. The stress value $(\varepsilon)$ is obtained by dividing the compression load by the initial area of the section perpendicular to the compression axis, while the strain value $(\sigma)$ is obtained by dividing the change of length (equal to the crosshead displacement) by the initial length parallel to the compression axis. The $\varepsilon-\sigma$ curves obtained in radial compression tests of uninoculated and inoculated cork cubes show three typical regions found in the compression of a flexible foam (Fig. 2(a),(b)): the first, low-strain region, corresponds to the reversible bending of the cell walls. When a critical stress is reached $\left(\varepsilon_{\mathrm{c}}\right)$, the cell walls start to buckle and the slope of the compression curve decreases. Finally, when cell-wall buckling is complete, the cell walls make contact with each other and the slope again increases $\left(\varepsilon_{\mathrm{f}}\right)$ (Rosa and Fortes, 1988). Although all specimens tested were of good

Table 1

Growth of fungi on cork-containing agar medium and into cork cubes (mean of triplicates)

\begin{tabular}{llll}
\hline & $\begin{array}{l}\text { Linear hyphal growth } \\
\text { rate on cork agar medium } \\
\left(\mathrm{mm} \mathrm{h}^{-1} \pm 0.01\right)\end{array}$ & $\begin{array}{l}\text { Depth of penetration } \\
\text { of hyphal growth into } \\
\text { cork (mm) }\end{array}$ \\
\cline { 3 - 4 } & & 14 days & \multicolumn{1}{c}{6 months } \\
\hline C. sitophila & 2.05 & $\leqslant 0.2$ & 2.6 \\
M. plumbeus & 0.36 & $\mathrm{ND}$ & $\mathrm{ND}$ \\
P. glabrum & 0.35 & $\leqslant 0.2$ & 3.2 \\
$\begin{array}{l}\text { P. olsonii } \\
\text { T. longibrachiatum }\end{array}$ & 0.15 & $\mathrm{ND}$ & $\mathrm{ND}$ \\
& 1.00 & $\leqslant 0.2$ & 3.8 \\
\hline
\end{tabular}

ND, not determined.
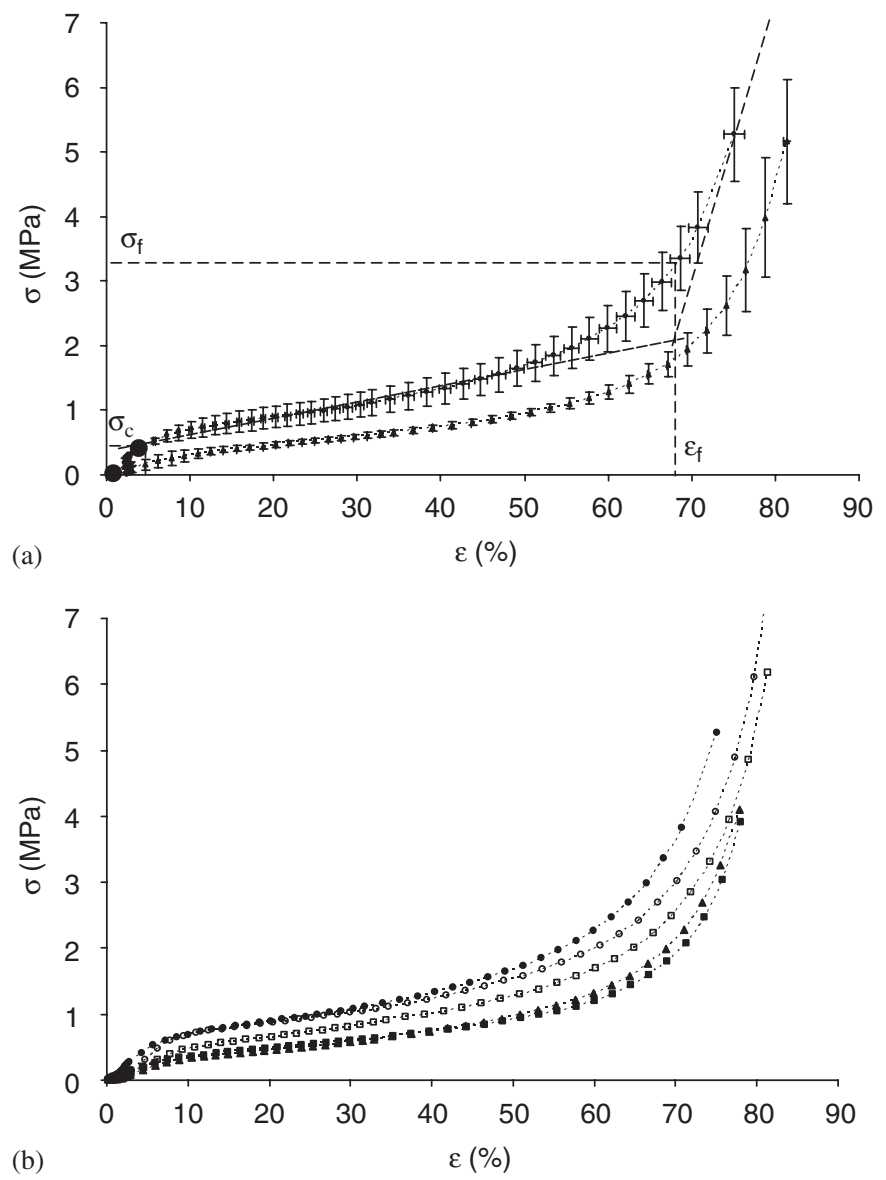

Fig. 2. (a) Average radial stress - strain curves for non-inoculated cork cubes $\left(\right.$ ca. $\left.8 \mathrm{~cm}^{3}\right)$ and $P$. glabrum inoculated cork cubes cubes $(\bullet$, control; $\boldsymbol{\Delta}$, P. glabrum). Bars indicate the standard deviation between replicates (2 and 3, respectively). Tangent lines to the stress - strain curve for the noninoculated cork cubes are represented by a discontinuous trace, $\sigma_{\mathrm{c}}, \varepsilon_{\mathrm{c}}, \sigma_{\mathrm{f}}$ and $\varepsilon_{\mathrm{f}}$ are also indicated; (b) Average radial strain - stress curves for non inoculated and inoculated cork cubes $(\bullet$, control; $\bigcirc, C$. sitophila; $\square, M$. plumbeus; $\boldsymbol{\Delta}$ P. olsonii; $\mathbf{\square}$, T. longibrachiatum).

industrial quality, the heterogeneity of the cork tissues still introduced some scatter, (higher in inoculated specimens), in the compression tests. The average $\varepsilon-\sigma$ curve showed an increased standard deviation between replicates with increased strain, but typical standard deviations were $<0.15$ for $\varepsilon$ and $<0.35$ for $\sigma$, validating the results (Table 2). All inoculated cubes, except for those with $C$. sitophila, (which exhibited the least effect), showed lower strength, than the uninoculated cubes. This significantly altered the radial $\varepsilon-\sigma$ behaviour and influenced both the $\varepsilon_{\mathrm{c}}$ and $\varepsilon_{\mathrm{f}}$ parameters of the typical cork radial compression curve (Fig. 2(a,b), Table 2). The coefficient, $\sigma_{\mathrm{c}} / \varepsilon_{\mathrm{c}}$ (Young's modulus, $E$ ) is normally considered an intrinsic characteristic of the material tested (Fortes et al., 2004). Reduction of compression strength for boiled cork has previously been reported (Rosa et al., 1990), and in the present investigation uninoculated boiled cork (Table 2) had a lower $E$ (approx. 9) than non-boiled cork, for which $12 \mathrm{MPa}$ has been recorded (Fortes et al., 2004). Structural alterations that reduce cork strength, giving lower $E$ values, 
appeared here to occur concomitantly with fungal colonization, although as stated above the effect of $C$. sitophila was limited.

\subsection{Penetration of different cork cellular layers by fungal mycelium}

The process of cork decay by three of the fungi, $C$. sitophila, P. glabrum and T. longibrachiatum, was further

\section{Table 2}

Values of $\varepsilon_{\mathrm{c}}$ and $\varepsilon_{\mathrm{f}}$ and respective $\sigma_{\mathrm{c}}$ and $\sigma_{\mathrm{f}}$ for uninoculated and three months inoculated $8-\mathrm{cm}^{3}$ cork cubes

\begin{tabular}{lllllllll}
\hline Fungi isolate & $\varepsilon_{\mathrm{c}}$ & $\sigma_{\mathrm{c}}$ & $E$ & $\varepsilon_{\mathrm{f}}$ & $\sigma_{\mathrm{f}}$ & \multicolumn{2}{l}{ Standard deviation } \\
\cline { 5 - 8 } & & & & & & $\varepsilon$ & $\sigma$ \\
\hline Negative control & 6.01 & 0.54 & 9.0 & 63.9 & 2.7 & 0.40 & 0.15 \\
C. sitophila & 6.34 & 0.51 & 8.1 & 69.0 & 2.9 & 0.50 & 0.30 \\
M. plumbeus & 6.67 & 0.25 & 5.0 & 70.0 & 2.1 & 0.40 & 0.15 \\
T. longibrachiatum & 6.23 & 0.28 & 4.4 & 67.0 & 1.6 & 1.70 & 0.17 \\
P. olsonii & 7.63 & 0.25 & 3.8 & 66.8 & 1.7 & 0.90 & 0.07 \\
P. glabrum & 8.51 & 0.42 & 3.3 & 69.0 & 2.4 & 0.04 & 0.12 \\
\hline
\end{tabular}

$E$, corresponds to Young's modulus $\left(\sigma_{\mathrm{c}} / \varepsilon_{\mathrm{c}}\right)$ for non-inoculated and inoculated cork. characterized by microscopical studies. Superficial fungal growth was visible to the naked eye after about 7 days, and optical microscopy additionally revealed growth in the lenticellular channels of cork sections after 21 days (data not shown). So as to better understand the relationship between the fungal hyphae and the cork cells, inoculated cork tissues were also examined by fluorescence microscopy. The cork cell walls exhibited green auto-fluorescence in the UV to the infrared region with higher intensity at $510-610 \mathrm{~nm}$ (data not shown). This obstructs the differentiation of frequently used fluorophores, but good discrimination between the fungal hyphae (fluorescing red) and the cork cell wall was achieved in the far infrared region when the chitin-labelling wheat germ agglutinin (WGA) conjugated with the fluorophore (peak emission at $690 \mathrm{~nm}$ ) was used on the thin transverse sections taken from $200-\mu \mathrm{m}$ thick sections (Fig. 3). This approach clearly differentiated between fungal elements and the cork cells with their green-fluorescing irregular cell walls of about $1.0-1.5 \mu \mathrm{m}$ thick. After 14 days, C. sitophila, P. glabrum and $T$. longibrachiatum had not only grown over the surface of the cork, but had penetrated to the depth of at least one layer of cells into the cork thick sections (the high opacity of the cork cell walls limits the penetration of the
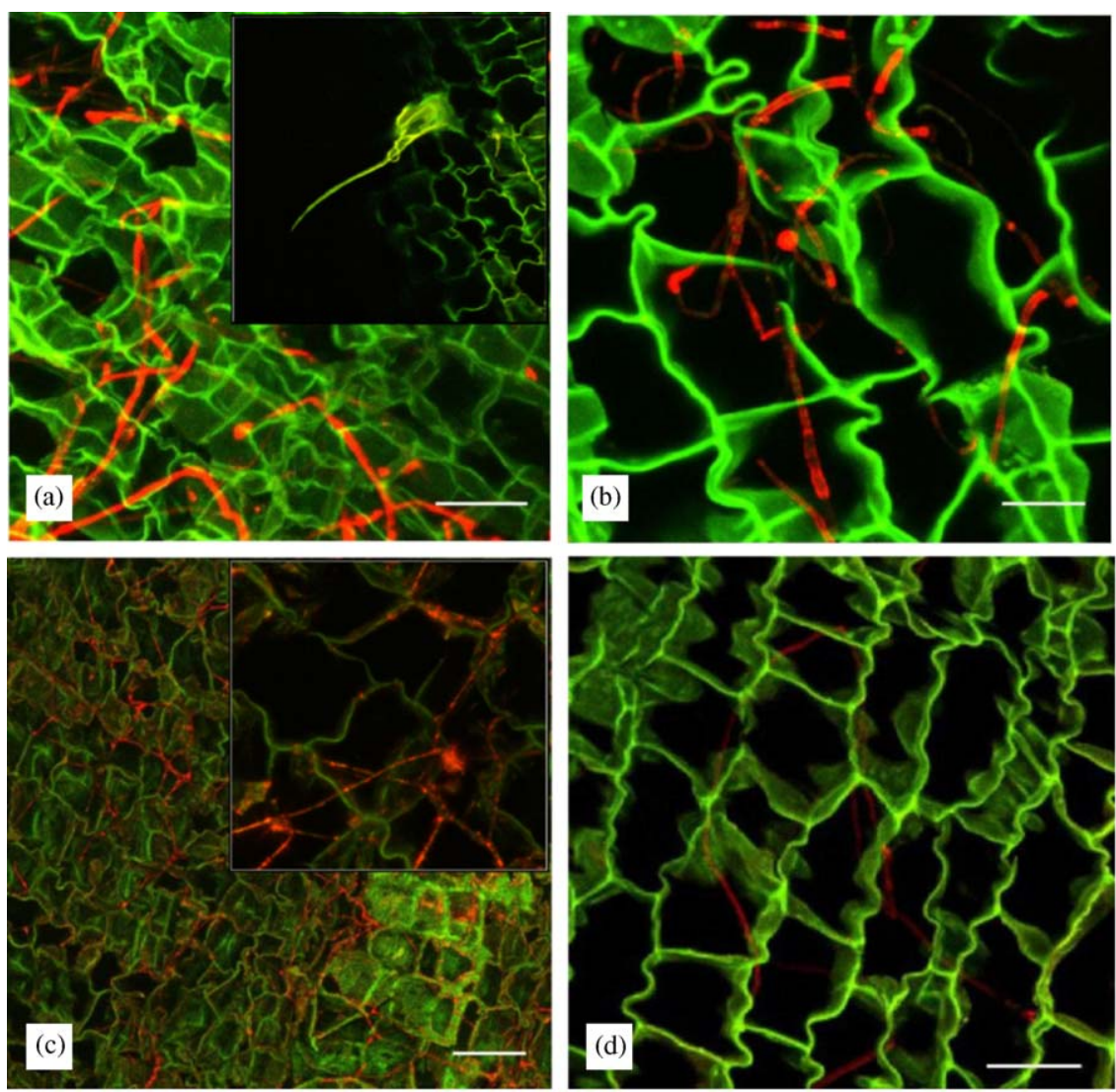

Fig. 3. Fungal colonization of inoculated thick $(200-\mu \mathrm{m})$ sections of cork (seen in thin transverse sections, with hyphae red, cork cell walls green): (a) $C$. sitophila at 14 days; inner box shows detail of $C$. sitophila colonization with binding between the fungal structure and cork cells as a green bleed (green fluorescence is due to use of acridine orange as fluorophore); bar $=40 \mu \mathrm{m}$; (b) P. glabrum at 14 days; bar $=20 \mu \mathrm{m}$; (c) T. longibrachiatum at 14 days; inner box shows higher magnification an adhesion structure; bar $=50 \mu \mathrm{m}$; (d) T. longibrachiatum at 6 months; bar $=30 \mu \mathrm{m}$. 
laser to one cellular layer). The colonizing hyphae in the tissues showed a net-like pattern apparently preferentially located over the cell walls (e.g. Fig. 3(a),(c)). In the case of C. sitophila (Fig. 3(a)), it appeared that the fungi bound to the cork cells through a modified adhesion structure (see inner box). Microscopy at maximum magnification shows that the hyphae penetrated the cork cells (e.g. Fig. 3(b),(c)).

When the depth of hyphal penetration by the three fungi into the cork cube by the time of fluorescence analysis (6 months) was evaluated by tangential or transverse sectioning of $200-\mu \mathrm{m}$ thick sections, the limit of penetration (recorded as being approximately equivalent to the number of the last thick section in which hyphae were detected) was 2.6-3.8 mm, depending on species (Table 1). In comparison, after 14 days mycelium could only be detected in the first thick section (Table 1). The colonization of a deeper thick section by $T$. longibrachiatum is depicted in Fig. 3(d).

In conclusion, it can be said that although the mycelial progression of the three fungi to deeper cork layers broadly reached the same depth in the cork, it resulted in different effects on its mechanical performance. The extent of the mycelial penetration therefore does not appear to be the cause of the observed compression strength differences. This effect is apparently time-related, given that further doubling the incubation time reduced the strength of the specimens (data not shown). All fungi have grown well on cork-based media, but apparently no correlation exists between growth rate and effect on cork mechanical performance. Interestingly, all colonizing fungi, except $C$. sitophila, reduced cork strength. The differences observed in cork mechanical performances might correlate with cork large variability in suberin and polysaccharide (Lopes et al., 2001). Thus it may be suggested that the fungal effect on cork mechanical performance is somehow correlated with the specificity of the decay, thus primarily controlled by the biodegradability of each cork cell wall constituents. The fungal species tested may degrade both cellulose and lignin (for e.g. Penicillium spp. (Lynd et al., 2002, Rodriguez, 1994, p. 258); T. longibrachiatum (Kubicek et al., 1996); Mucor plumbeus (Milstein et al., 1983) and C. sitophila (Orth et al., 1993; Rodriguez et al., 1997; Vitorino et al., 2002)). Likewise, although suberin is considered very recalcitrant to fungal degradation it was for e.g. recently observed that $C$. sitophila, isolated from cork wine stoppers, showed high esterase and lipase activity (Centeno and Calvo, 2001). Analysis of the consumption rate of each cork cell wall constituent during fungi colonization will be important to further understand the specificity of cork decay by fungi, especially when concerning cork main constituent: suberin, which is responsible for cork visco-elastic behaviour. Confocal microscopy with specific antibodies raised against specific depolymerising enzymes of particular species could also be used to distinguish between the different enzymatic mechanisms involved in cork decay.

\section{Acknowledgements}

This work was partially supported by Amorim and Irmãos (Sta. Maria de Lamas, Portugal). The authors wish to acknowledge M.C. Basílio and R. Gaspar for assistance in experimental development and analysis of data.

\section{References}

Alvarez-Rodriguez, M.L., Lopez-Ocana, L., Lopez-Coronado, J.M., Rodriguez, E., Martinez, M.J., Larriba, G., Coque, J.-J.R., 2002. Cork taint of wines: role of the filamentous fungi isolated from cork in the formation of 2,4,6-trichloroanisole by $O$ methylation of 2,4,6trichlorophenol. Applied and Environmental Microbiology 68, $5860-5869$.

Blanchette, R.A., 2000. A review of microbial deterioration found in archaeological wood from different environments. International Biodeterioration \& Biodegradation 46, 189-204.

Carlite, M., Watkinson, S., 1994. Saprotrophs and Ecosystems. Academic Press Limited, New York.

Centeno, S., Calvo, M., 2001. Enzymatic activity of micro-organisms isolated from cork wine stoppers. Microbios 106, 69-73.

Clause, C., 1997. Immunological detection of wood decay fungi-an overview of techniques develop from 1986 to the present. International Biodeterioration \& Biodegradation 39, 133-143.

Coque, J.-J.R., Alvarez-Rodriguez, M.L., Larriba, G., 2003. Characterization of an inducible chlorophenol $O$-methyltransferase from trichoderma longibrachiatum involved in the formation of chloroanisoles and determination of its role in cork taint of wines. Applied and Environmental Microbiology 69, 5089-5095.

Danesh, P., Velez Caldas, F., Figueiredo Marques, J., San Romao, M., 1997. Mycobiota in Portuguese 'normal' and 'green' cork throughout the manufacturing process of stoppers. Journal Applied Microbiology 82, 689-694.

Fortes, M., Rosa, M.E., Pereira, H., 2004. A Cortiça. IST Press, Lisboa.

Geoffrey, D., 1994. Use of electron microscopy for aiding our understanding of wood biodegradation. FEMS Microbiology Reviews 13, 199-233.

Kolattukudy, P., 1981. Structure, biosynthesis, and biodegradation of cutin and suberin. Annual Review Plant Physiology 32, 539-567.

Kubicek, C.P., Bolzlbauer, U.M., Kiovacs, W., Mach, R.L., Kuhls, K., Lieckfeldt, E., Borner, T., Samuels, G.J., 1996. Cellulase formation by species of Trichoderma sect. Longibrachiatum and of Hypocrea spp. with anamorphs referable to Trichoderma sect. longibranchiatum. Fungal Genetics and Biology 20, 105-114.

Lopes, M., Barros, A., Pascoal Neto, C., Rutledge, D., Delgadillo, I., Gil, A., 2001. Variability of cork from Portuguese Quercus suber studied by solid-state ${ }^{(13)} \mathrm{C}-\mathrm{NMR}$ and FTIR spectroscopies. Biopolymers 62, 268-277.

Lopes, M., Neto, C., Barros, A., Rutledge, D., Delgadillo, I., Gil, A., 2000. Quantitation of aliphatic suberin in Quercus suber L. cork by FTIR spectroscopy and solid-state ${ }^{(13)} \mathrm{C}-\mathrm{NMR}$ spectroscopy. Biopolymers $57,344-351$.

Lynd, L.R., Weimer, P.J., van Zyl, W.H., Pretorius, I.S., 2002. Microbial Cellulose Utilization: Fundamentals and Biotechnology. Microbiology and Molecular Biology Reviews 66, 506-577.

Mano, J., 2002. The viscoelastic properties of cork. Journal of Materials Science 37, 257-263.

Milstein, O.A., Vered, Y., Sharma, A., Gressel, J., Flowers, H.M., 1983. Fungal biodegradation and biotransformation of soluble lignocarbohydrate Complexes from straw. Applied and Environmental Microbiology 46, 55-61.

Oliveira, A., Peres, C., Correia Pires, J., Silva Pereira, C., Vitorino, S., Figueiredo Marques, J., Barreto Crespo, M.T., San Romão, M., 2003. Cork stoppers industry: defining appropriate mould colonization. Microbiological Research 158, 117-124. 
Orth, A.B., Royse, D., Tien, M., 1993. Ubiquity of lignin-degrading peroxidase among various wood-degrading Fungi. Applied and Environmental Microbiology 59, 4017-4023.

Pereira, H., 1988. Chemical composition and variability of cork from Quercus suber L. Wood Science and Technology 22, 218-221.

Pereira, H., Rosa, M.E., Fortes, M., 1987. The cellular structure of cork from Quercus suber L. IAWA Bulletin 8, 213-218.

Riu, H., Roig, G., Sancho, J., 1997. Production of carpophores of Lentinus edodes and Ganoderma lucidum grown on cork residues. Microbiologia 13, 185-192.

Rodriguez, J., Ferraz, A., Nogueira, R.F., Ferrer, I., Espositio, E., Duran, N., 1997. Lignin biodegradation by the ascomycete Chrysonilia sitophila. Applied and Environmental Microbiology 62, 233-242.

Rosa, M., Fortes, M., 1988. Rate effects on the compression and recovery of dimensions of cork. Journal Materials Science 23, 879-885.

Rosa, E., Pereira, H., Fortes, M., 1990. Effects of hot water treatment on the structure and properties of cork. Wood and Fiber Science 22, 149-169.
Silva Pereira, C., Figueiredo Marques, J., San Romão, M., 2000a. Cork taint in wine: scientific knowledge and public perception: a critical review. Critical Reviews in Microbiology 26, 147-162.

Silva Pereira, C., Pires, A., Valle, M., Vilas-Boas, L., Figueiredo Marques, J., San Romão, M., 2000b. Role of Chrysonilia sitophila on the quality for cork stoppers for sealing wine bottle. Journal of Industrial Microbiology and Biotechnology 24, 256-261.

Soares, G., Basilio, M., Tenreiro, R., San Romão, M., 2003. Diversity of Penicillium spp. colonizing cork slabs: a classical and molecular approach. In: Lima, N., Smith, D. (Eds.), Biological Resource Centres and the Use of Microbes-XXII ECCO Meeting Proceedings Book. MUM, Braga, pp. 161-170.

Vitorino, S., Almeida-Vara, E., Tenreiro, R., San Romão, M., 2002. Optimisation of expression conditions of cellulolytic complex from Chrysonilia sitophila. In: Congresso Mundial do Sobreiro e da Cortiça Proceedings Book. AGROGES, Lisboa, pp. $458-460$. 